\title{
Publisher Correction: A recent decline in North Atlantic subtropical mode water formation
}

Samuel W. Stevens (iD, Rodney J. Johnson, Guillaume Maze (D) and Nicholas R. Bates

Correction to: Nature Climate Change https://doi.org/10.1038/s41558-020-0722-3, published online 23 March 2020.

In the version of this Article originally published, in Fig. $2 \mathrm{~d}$ and $\mathrm{f}$, in all the $y$-axis values ' $\times 10^{-7}$ ' was incorrect and should have been ' $\times 10^{7}$. This error has now been corrected in the online versions of this Article.

Published online: 22 September 2020

https://doi.org/10.1038/s41558-020-00932-4

(C) The Author(s), under exclusive licence to Springer Nature Limited 2020 